\title{
Practical Aspects of the Resin Bead Technique for Mass Spectrometric Sample Loading
}

\author{
R. L. Walker \\ C. A. Pritchard \\ J. A. Carter \\ David H. Smith
}

\section{OAK RIDGE NATIONAL LABORATORY}




\section{DISCLAIMER}

This report was prepared as an account of work sponsored by an agency of the United States Government. Neither the United States Government nor any agency Thereof, nor any of their employees, makes any warranty, express or implied, or assumes any legal liability or responsibility for the accuracy, completeness, or usefulness of any information, apparatus, product, or process disclosed, or represents that its use would not infringe privately owned rights. Reference herein to any specific commercial product, process, or service by trade name, trademark, manufacturer, or otherwise does not necessarily constitute or imply its endorsement, recommendation, or favoring by the United States Government or any agency thereof. The views and opinions of authors expressed herein do not necessarily state or reflect those of the United States Government or any agency thereof. 


\section{DISCLAIMER}

Portions of this document may be illegible in electronic image products. Images are produced from the best available original document. 
Printed in the United States of America. Available from

National Technical Information Service

U.S. Department of Commerce

5285 Port Royal Road, Springfield, Virginia 22161

Price: Printed Copy \$4.00; Microfiche $\$ 2.25$

This report was prepared as an account of work sponsored by the United States Government. Neither the United States nor the Energy Research and Development Administration/United States Nuclear Regulatory Commission, nor any of their employees, nor any of their contractors, subcontractors, or their employees, makes any warranty, express or implied, or assumes any legal liability or responsibility for the accuracy, completeness or usefulness of any information, apparatus, product or process disclosed, or represents that its use would not infringe privately owned rights. 
ORNL/TM-5505

\author{
Contract No. W-7405-eng-26 \\ ANALYTICAL CHEMISTRY DIVISION \\ PRACTICAL ASPECTS OF THE RESIN BEAD \\ TECHNIQUE FOR MASS SPECTROMETRIC \\ SAMPLE LOADING
}

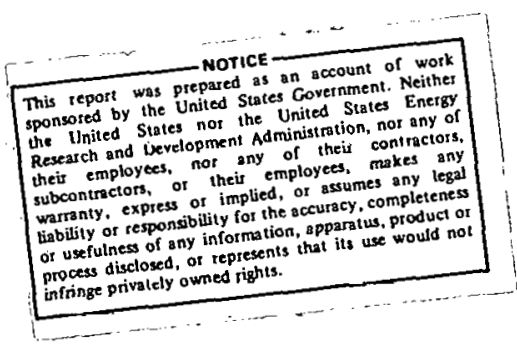

R. L. Walker, C. A. Pritchard, J. A. Carter, and David H. Smith

JULY 1976

OAK RIDGE NATIONAL LABORATORY

Oak Ridge, Tennessee

operated by

UNION CARBIDE CORPORATION

for the

Energy Research and Development Administration

DISTRIBUTION OF THIS DOCUMENT IS UNLIMITED $\sum^{\sum B}$ 
THIS PAGE

\section{WAS INTENTIONALLY \\ LEFT BLANK}




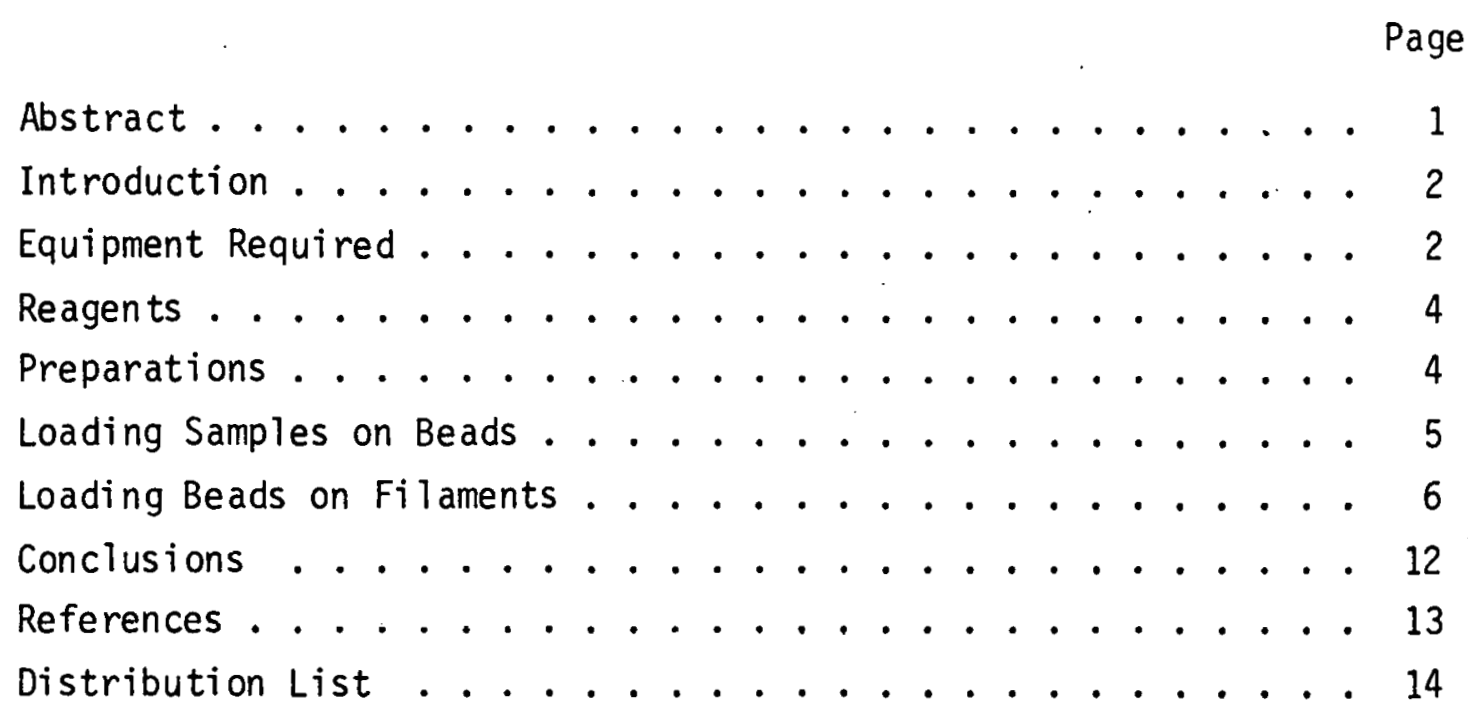




\section{THIS PAGE}

\section{WAS INTENTIONALLY LEFT BLANK}




\section{LIST OF FIGURES}

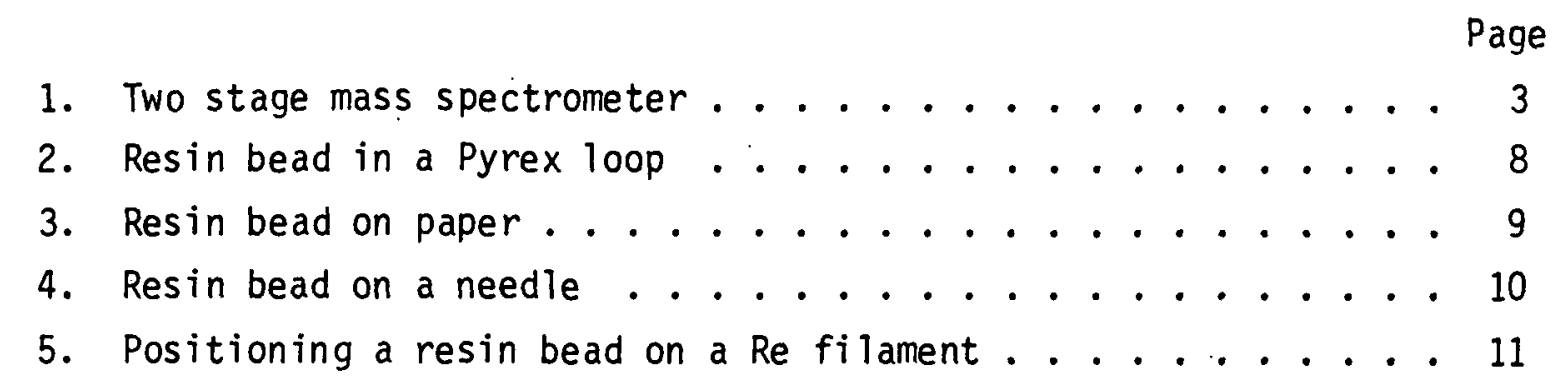




\section{ABSTRACT}

Using an anion resin bead as a loading vehicle for uranium and plutonium samples which are to be analyzed isotopically in a mass spectrometer has many advantages over conventional techniques. It is applicable to any laboratory routinely performing such analyses, but should be particularly relevant for Safeguards' purposes. Because the techniques required differ markedly from those of conventional methods, this report has been written to describe them in detail to enable those unfamiliar with the technique to master it with a minimum of trouble. 


\section{PRACTICAL ASPECTS OF THE RESIN BEAD \\ TECHNIQUE FOR MASS SPECTROMETRIC \\ SAMPLE LOADING}

\section{Introduction}

The intention of this report is to describe some of the practical problems involved in implementing the resin bead sample loading technique for mass spectrometric analysis of uranium and plutonium, described recently by walker, et al. 1,2 The technique seems to have tremendous potential for application to Safeguards samples. Its principal advantages, when compared to conventional techniques, are:

1. Dramatic reduction in time and money required for chemical separation.

2. Reduction of radiation hazards because only small quantities of sample need to be handled.

3. Reduction of transportation costs by reducing the amount of radioactive material to be shipped.

4. More reliable ${ }^{238} \mathrm{Pu}$ data.

These advantages have been discussed by Walker, et al. at some length in their papers and will not be pursued here.

Equipment Required

1. First and foremost, a mass spectrometer with sufficient sensitivity to analyze uranium samples in the 1-10 $\mathrm{ng}$ range. This requires a pulse-counting detection system. To obtain accurate minor isotope values, the instrument should diso have an abundance scnsitivity of $=10^{6}$. Such instruments have beell previuusly described, 3,4 and a photograph of one is shown in Figure 1.

2. A laminar flow hond in which to mount microscopes and do the sample handling. This helps significantly in keeping the sample apparatus clean, which is crucial for this operation.

3. A good (medium power) microscope. ORNL uses a Wild M5-Pol binocular microscope. Most of the resin bead handling is done with the help of this microscope. 


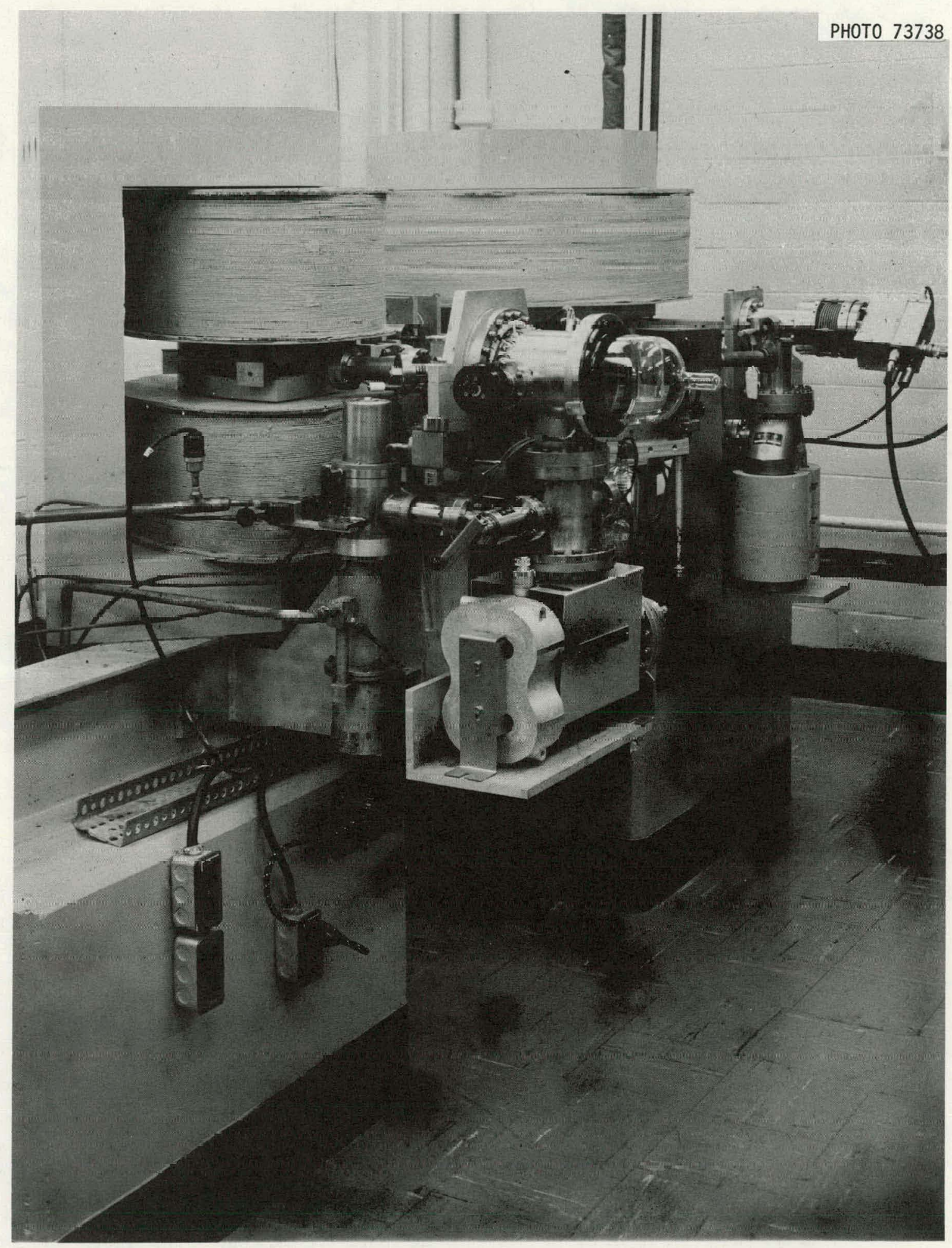

Fig. 1. Two stage mass spectrometer. 
4. A lower power microscope to use when actually putting resin beads on filaments. ORNL uses a Bausch and Lomb Model YB6145 stereomicroscope; a three-dimensional image is very helpful in this operation.

5. An assortment of needles, preferably, but not necessarily, of tungsten or stainless steel, mounted in handles.

6. Dowex $1,2 \%$ cross 1 inked, 100-200 mesh anion resin in the chloride form.

7. Pyrex tubing, $n, 6 \mathrm{~mm}$ in diameter.

8. Clean microscope slides. ORNL uses precleaned Gold Seal, Model 3010 slides provided by $\mathrm{Cl}$ ay Adams Division of Becton-Dickinson Company, Parsippany, New Jersey, U. S. A.

9. Centrifuge cones of 2 or $3 \mathrm{ml}$ volume. Stoppers from volumetric flasks can be used for these cones. These items should be thoroughly leached in $8 \underline{\mathrm{M}} \mathrm{HNO}_{3}$ before using.

\section{Reagents}

1. All $\mathrm{HNO}_{3}$ should be redistilled at the laboratory in a quartz still to obtain the necessary purity. Start with analytical grade $\mathrm{HNO}_{3}$.

2. All water used should be triple-distilled.

\section{Preparations}

1. It is extremely important to keep the entire working area scrupulously clean. Not only do foreign particles lead to sample contamination, but they can render identification of the single resin bead of interest extremely difficult. It is for this reason that a laminar flow hood is strongly recommended.

2. One of the most useful luols in manipulaling resin beads is a fine Pyrex loop. They are made from $26 \mathrm{~mm}$ Pyrex tubing (which has been found to be easier to use than rod) by first heating the conter of the tubing until it coalesces to a rod and then drawing it out to a diameter of about $0.5 \mathrm{~mm}$. The rod is allowed to cool while being held straight and then gently warmed until it can be pulled apart. Hopefully a loop will be formed at the tip of the fine rod. As one might expect, there is considerable art involved here, and a sub- 
stantial number of failures. The critical parameters are the velocity with which the glass is pulled apart and its temperature. On a good day, an experienced person can expect to make one loop in 15 minutes. The work requires patience and steady hands, and probably should not be continued for more than two or three hours. The loops thus formed are of variable size, but some will be of appropriate geometry for resin beads of a given diameter.

3. A few Pyrex probes, made while making loops, are also very useful.

4. Transfer pipets, made from $6 \mathrm{~mm}$ Pyrex, are also needed.

5. All glassware should be soaked in the same medium the samples will be in, i.e., 6-8 $\mathrm{MNO}_{3}$. When an item is to be used, it should be rinsed with triple distilled water and left in an oven until it is needed.

6. Resin beads should be conditioned by soaking in $8 \underline{\mathrm{M}} \mathrm{HNO}_{3}$ at least two days before use; they can remain thus indefinitely. Do not discard an old batch of beads before the new one has been verified to be suitable for use.

7. The resin bead-8 $\mathrm{MNO}_{3}$ mixture should be kept in a plastic (polypropylene) container. $\mathrm{HNO}_{3}$ leaches uranium out of glass and thus introduces contamination.

Loading Samples on Beads

Extract a number of conditioned resin beads from the acid with a clean transfer pipet and deposit them on a clean microscope slide. It will take about 30 minutes for the beads to reach optimum dampness - they should be wet, but with no water standing on the slide. Beads that are too wet cling to each other and are virtually impossible to work with individually. Beads that are too dry become electrostatically charged and are also virtually impossible to control.

While waiting for the beads to reach suitable wetness, carefully clean the microscope stage with a lint-free wiper and triple-distilled water. Kimwipes are suitable for this purpose. It is extremely important to keep the stage clean. 
The liquid sample should be held in $0.1-0.2 \mathrm{ml}$ of solution placed in a 2 or $3 \mathrm{ml}$ centrifuge cone. Too much liquid makes manipulation of the beads difficult. Thus, the concentrations of uranium and plutonium should be adjusted to give about $10^{-6} \mathrm{~g}$ of $\mathrm{U}$ and $10^{-8} \mathrm{~g}$ of $\mathrm{Pu}$ in a 0.1-0.2 $\mathrm{ml}$ aliquot; acid concentration should be 7-8 $\mathrm{M} \mathrm{HNO}_{3}$. If total $\mathrm{U}$ or $\mathrm{Pu}$ is desired, the sample should be spiked prior to its transfer to the centrifuge cone.

When the beads are ready, use a fine glass rod to segregate some of those of roughly equal size, viewing the operation through the microscope. Separate these into bundles containing the number of beads you want to put into each sample (usually 3-10). There should be enough sample to give 1 $\mathrm{ng}$ of $\mathrm{Pu}$ and 5-10 $\mathrm{ng}$ of $U$ on each bead. Pick up each bundle of beads ( 5 beads can be picked up simultaneously) with the glass rod and put them into the sample by gently touching the tip against the glass below the liquid leve1. Verify the position of the beads through the microscope. The beads should stand 24-48 hours in the sample solution before an analysis is attempted.

Loading Beads on Filaments

Transferring beads to filaments is a tedious business and should be performed with ample time in hand. Steady hands are required, and any undue pressure makes it just that much more difficult to execute the delicate operations properly.

Get a wheel of filaments into position under the coarse microscopeonly operations involving filaments are done here. The other microscope can't be used for these hecause it must have a stage, which makes pusitioning a wheel under it impossible.

To isolate the beads, flick your finger gently against the bottom of the cone to splatter the liquid up on the glass. Some beads should stick to the side of the cone above the level of the liquid. It is a great advantage to have a clean cone to prevent water from remaining beaded on the glass surface, thus obscuring the beads.

Select a loop of appropriate size (one with a diameter about four times that of the beads) and, using the microscope, drop it around one of the beads on the wall of the cone. The surface tension of the liquid surrounding the 
bead will cause it to adhere to the loop, and it can be withdrawn from the cone. Figure 2 is a drawing of a bead in the loop. Still under the microscope, touch a Kimwipe (or other lint-free absorbent paper) to the loop, bringing the paper up from beneath the loop. If the geometry of the loop permits, it is a good idea to have it bending down a little. The bead, with decent luck, will move onto the paper as the liquid is absorbed. Figure 3 is a drawing of a bead on the paper. If the loop is too small, however, the bead will often remain behind and not transfer. Pick the bead up from the paper with a clean needle (buff with No. 600 (U. S. grade) sandpaper, clean thoroughly with triple-distilled water and acetone) and transfer it to the waiting filament. Figure 4 shows schematically a bead on a needle. Try to center the bead with respect to the rhenium canoe to optimize ion optics in the mass spectrometer, as indicated in Figure 5. Crimp the canoe with tweezers or hemostats -about five crimps is right. This operation helps keep the bead in place.

If the loop you used is a good one, rinse it with $8 \mathrm{M} \mathrm{HNO}_{3}$, tripledistilled water, acetone and use it on the next sample. A loop with good geometry is valuable and should be zealously cared for to prolong its life, which should be several months or more.

Long Term Sample Storage

If beads with sample on them are to be stored over a long period of time (months or years), a good way of doing so is to keep them under collodion on a glass microscope slide. Arrange the beads individually in an array of convenient dimensions on a clean slide and cover each with a small drop of collodion. Ten beads can easily be mounted on a slide with little chance of confusion.

To remove a bead, cut around it through the collodion with an Exacto knife or sharp needle-the collodion drop is in general too large to be loaded in its entirety. Gently pry the circumscribed area out with a needleuse great care, because it is easy to flick the bead off into space-and mount it directly on the filament.

The details of the technique for mass spectrometric analysis of the beads have been described in detail by Walker, et al. ${ }^{1,2}$ 


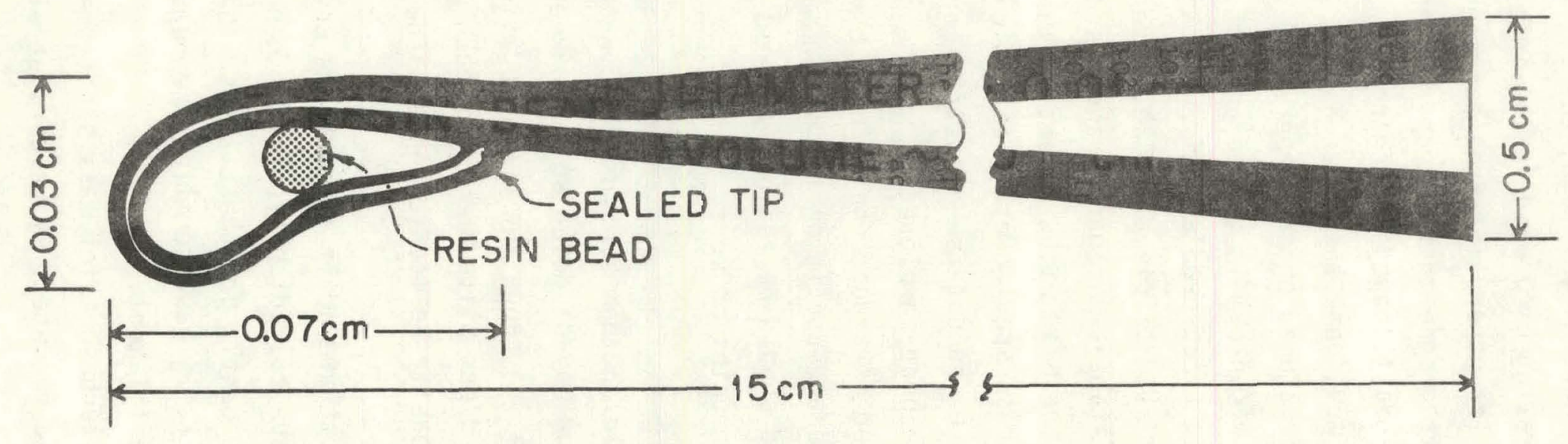

Fig. 2. Fesin bead in a Pyrex 1oop. 


\section{ORNL-DWG 75-11284}

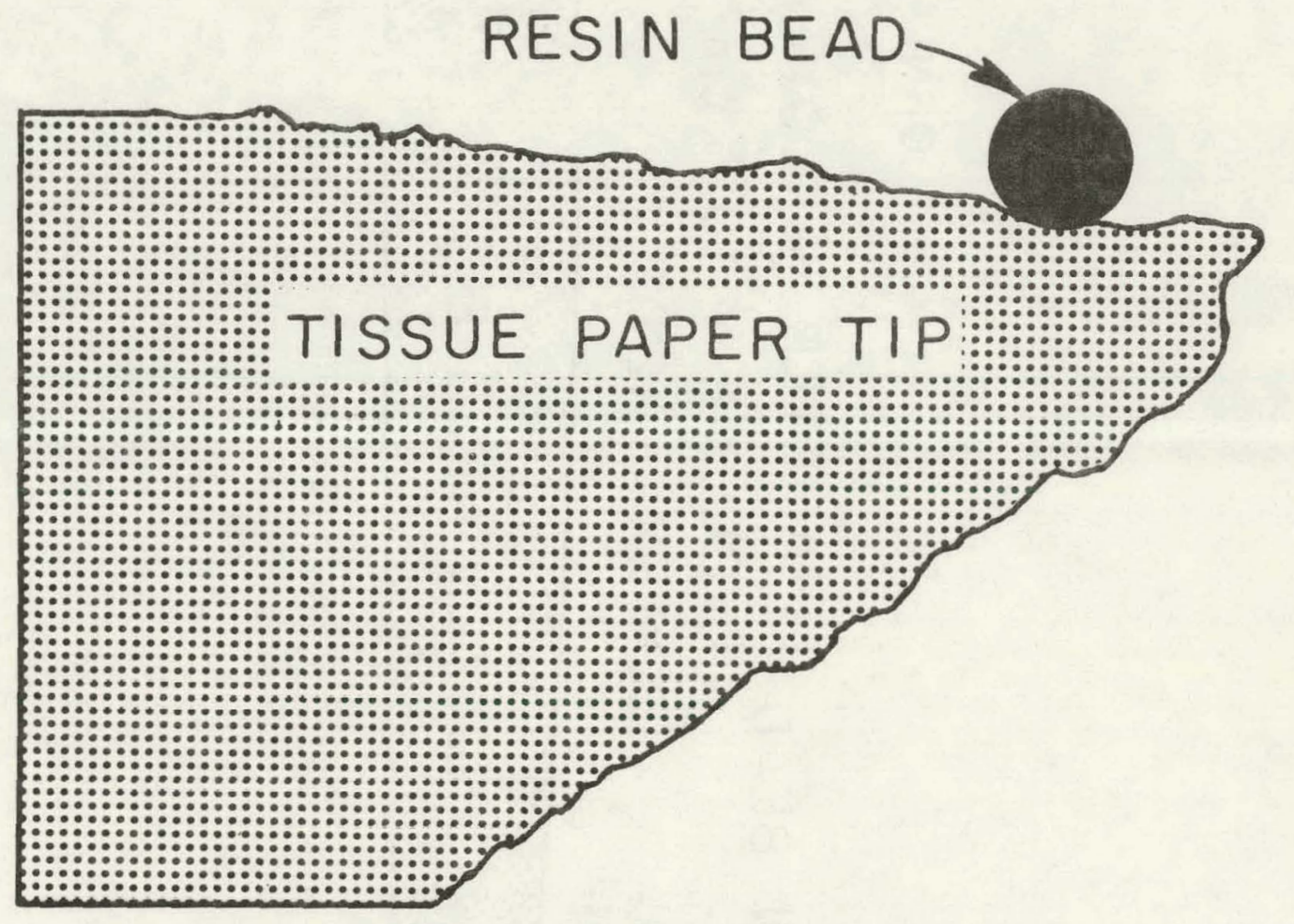

Fig. 3. Resin bead on paper. 
ORNL-DWG $75-11286$

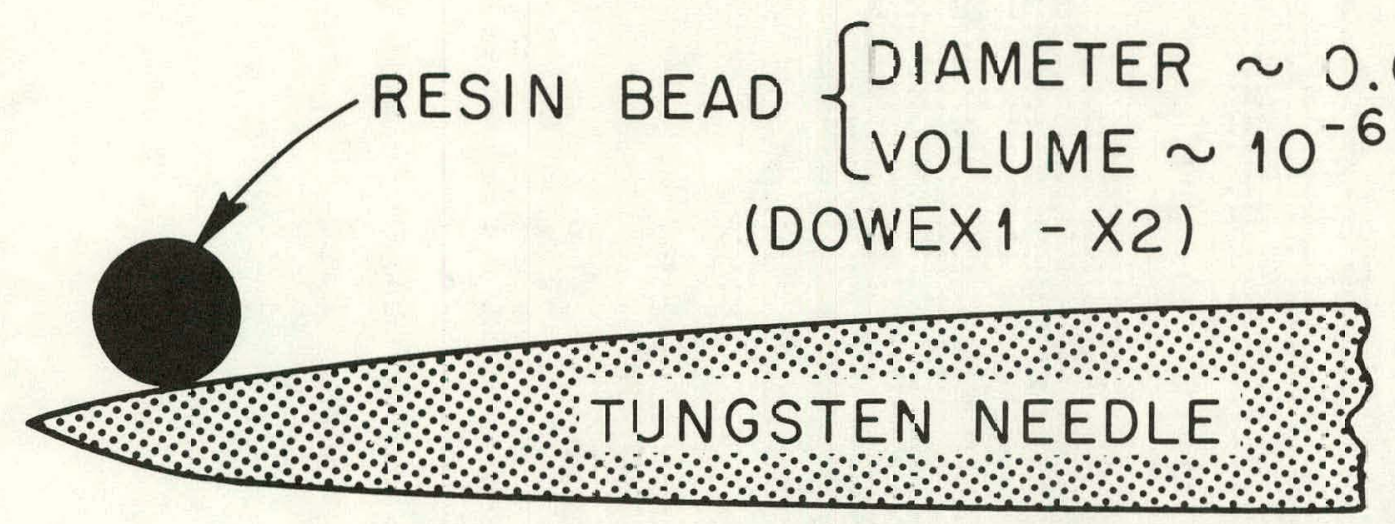

Fig. 4. Fiesin bead on a needle. 


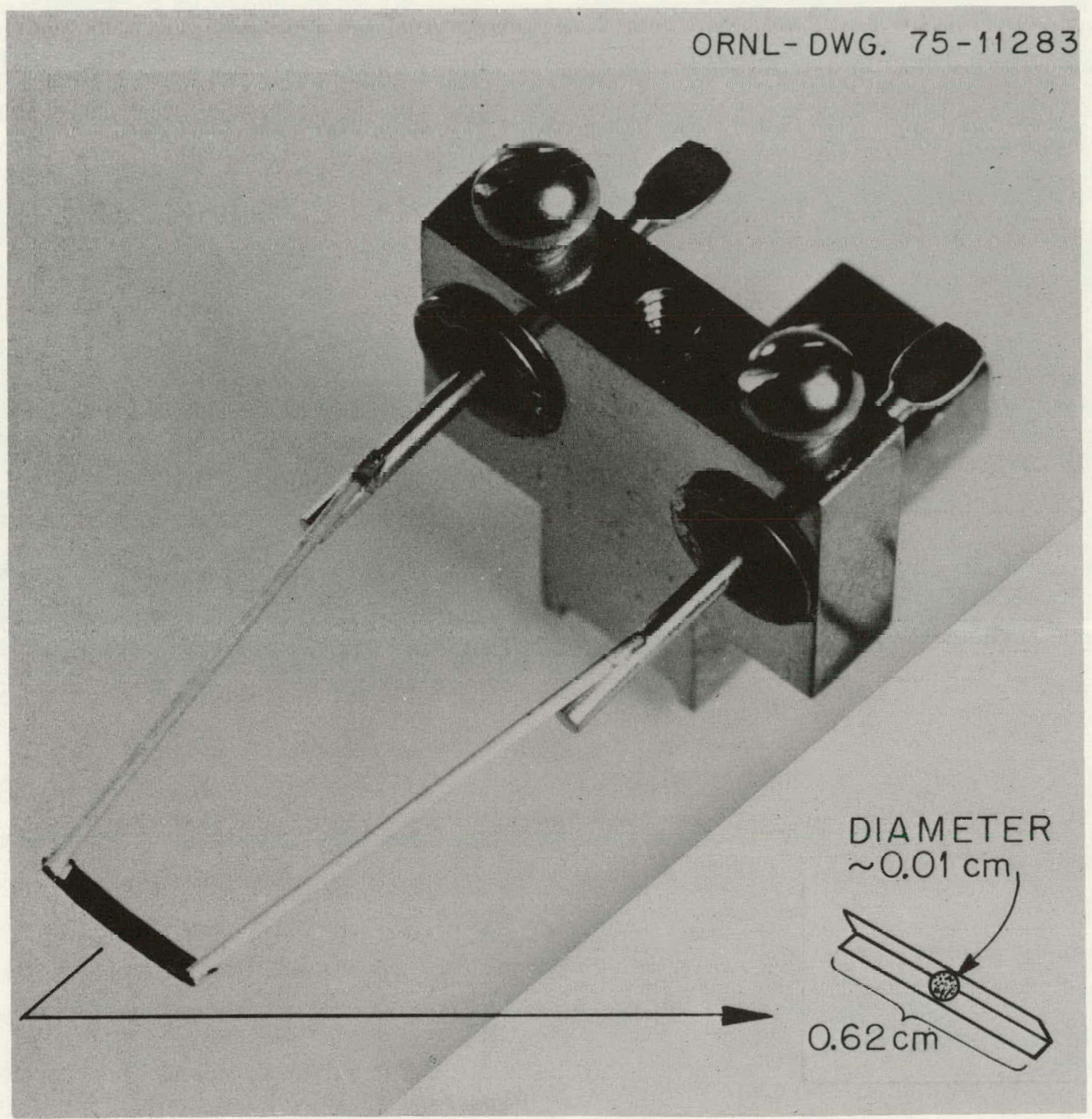

Fig. 5. Positioning a resin bead on a Re filament. 


\section{Conclusions}

The two primary requirements for the resin bead technique (aside from equipment) are cleanliness and time. Any dust in the microscope field renders location and identification of beads difficult, and, since the amounts of sample are so smal1, great care must be exercised to prevent contamination. Beads are so light and pick up electrostatic charge so readily that they easily migrate with air current. If a bead is lost, it should be located and discarded to eliminate any chance of it contaminating a 1 ater sample.

Even with experienced personnel, these operations are very slow. It takes a proficient technician 1-1/2 to 2 hours to load the six filaments on a sample wheel, and a considerable amount of time is required for cleaning up afterwards. But this time schedule is only valid if all goes well. Losing beads is a fact of life, and must be coped with. They can be lost at any stage in the proceedings, and each such loss requires additional time to locate the bead again.

Inserting beads into the sample solutions is somewhat faster than loading filaments, but it still takes about four hours to put beads into 15-20 samples.

Four huurs is ahout the maximum length of time a person can be expected to perform these operations. The demands on patience and skill are enormous, and it is very difficult to maintain the high standards required for longer periods. In fact, we consider that it would be unwise to have a technician whose only function was to do bead work. Nearly anyone can do the job with a little practice; we have three technicians at. ORNL who have been trained in this technique.

We do not claim that the details of the technique as outlined here are the only ones that would work, or even that they are the best ones. In fact, each of our three technicians uses slightly different variants; for instance, one of them uses only the loop while transferring beads to filaments. These instructions are intended to serve merely as guidelines, and it is to be expected that each technician will evolve an individual technique that best suits him. 


\section{REFERENCES}

1. R. L. Walker, R. E. Eby, C. A. Pritchard, and J. A. Carter, Anal. Letters I, 563 (1974).

2. J. A. Carter, R. L. Walker, R. E. Eby, and C. A. Pritchard, International Symposium on the Safeguarding of Nuclear Materials, Vienna, Austria, Oct. 1975, IAEA-SM-201/9. (Proceedings to be published.)

3. A. E. Cameron, W. H. Christie, H. S. Mckown, W. T. Rainey, and D. H. Smith, U. S. Atomic Energy Commission Report ORNL-4643, Oak Ridge, Tennessee, January 1971.

4. David H. Smith, W. H. Christie, H. S. McKown, R. L. Walker, and G. R. Herte1, Int. J. Mass Spec. and Ion Phys. 10, 343 (1972). 
THIS PAGE

\section{WAS INTENTIONALLY LEFT BLANK}


ORNL/TM-5505

\section{INTERNAL DISTRIBUTION}

1-2. Central Research Library

3-4. Laboratory Records Department

5. ORNL-RC

6. ORNL-Y-12 Technical Library Document Reference Section

7-25. J. A. Carter

26. W. H. Christie

27. F. L. Culler

28. R. E. Eby

29. J. C. Franklin

30. W. D. Harman

31. R. F. Hibbs

32. 0. H. Howard

33-40. P. R. Kasten

41. H. S. Mckown

42. H. Postma

43-62. C. A. Pritchard

63. W. T. Rainey

64. W. W. Rice

65. W. D. Shults

66-84. D. H. Smith

85. L. A. Smith

86-105. R. L. Walker

106. J. C. White

107. A. Zucker

EXTERNAL DISTRIBUTION

108. Director, Research and Terhniral Support Division, ERDA .ORO 109-135. Technical Information Center 